\title{
O uso dos estereótipos turísticos durante o regime militar brasileiro
}

\section{The use of tourist stereotypes during the Brazilian military regime}

\author{
Patrícia Fino \\ Universidade de São Paulo, Brasil \\ prof.patriciafino@hotmail.com \\ Odaléia Queiroz \\ Universidade de São Paulo \\ otmmquei@usp.br
}

\begin{abstract}
Resumo
Durante os anos de 1964 a 1985, o Brasil viveu sob uma ditadura militar, marcada por forte repressão política/ideológica. Esta pesquisa se propôs a investigar se os estereótipos turísticos foram utilizados como forma de promover a ideologia proposta pelos militares, com objetivo de obter um maior controle da população. Nesta etapa da pesquisa foram utilizados os seguintes procedimentos metodológicos: revisão bibliográfica e levantamento documental. Brasil: terra do sol e do mar, das belas mulheres, do povo alegre e hospitaleiro! Este foi o Brasil reiteradamente apresentado nos discursos correntes no período analisado. Nesta pesquisa, ainda em andamento, a história será revista e reexaminada. Acredita-se que o ineditismo e a importância histórica do tema justificam a relevância do trabalho proposto.
\end{abstract}

Palavras-chave: regime militar; turismo; estereótipo; manipulação.

\begin{abstract}
From 1964 to 1985 , Brazil was ruled by a military dictatorship, marked by strong political/ideological repression. This research aimed to investigate if the tourist stereotypes were used as a way to promote the ideology proposed by the military at a greater control of the population. The following methodological procedures were adopted: bibliographic review and documentary survey. Brazil: land of sun and sea, beautiful women, happy and hospitable people! This was the Brazil which was repeatedly presented in the everyday discourses during the analyzed period. In this research, still in progress, the history will be reviewed and reexamined. It is believed that the novelty and the historical importance of the theme justify the relevance of the work.
\end{abstract}

Keywords: military regime; tourism; stereotype; manipulation.

\section{Introdução}

A utilização dos meios de comunicação de massa com a finalidade de manipulação da população foi algo recorrente na história humana. Existem casos reconhecidos, como a Alemanha de Adolf Hitler (Domenach, 2005) e Portugal de António Salazar (Torgal \& Homem, 1982), em que os governos valeram-se dos meios de comunicação para tentar persuadir a sociedade. Hitler, inclusive, escreveu um livro intitulado Mein Kampf, em que tece considerações instrumentais de como proceder para obter o máximo de aproveitamento com a propaganda de massas. (Garcia, 1982).

Dos Algarves: A Multidisciplinary e-Journal, $30-2017$.

ISBN 2182-5580 @ ESGHT - University of the Algarve, Portugal.

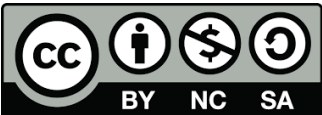


O termo "manipulação" utilizado neste artigo refere-se à definição proposta por Van Dijk (2008), que entende que a manipulação é uma prática comunicativa e interacional, em que ocorre um abuso de poder, sendo este abuso chamado por ele de dominação. Os manipuladores procuram fazer com que os manipulados ajam ou pensem de acordo com o interesse dos primeiros e contra seus próprios interesses, para isto utilizam-se dos discursos.

De acordo com Martins (1999), mesmo havendo uma enorme força repressiva aos que se opunham ao regime hitleriano, a utilização da propaganda foi fundamental para a construção da imagem e a consolidação do III Reich.

Porém, não é apenas durante regimes totalitários/autoritários que os governos valem-se deste artificio. Um estudo comparativo desenvolvido por Pereira (2012) mostra que, durante o mesmo período, uma ditadura de tipo totalitário (representada pelo governo nazista) e uma democracia de tipo liberal (representada pelo governo de Franklin Delano Roosevelt) utilizaram "o cinema como instrumento de cooptação e adestramento da opinião pública, dentro e fora dos respectivos países" (Pereira, 2012: 10).

Do mesmo modo, grande parte das sociedades contemporâneas, vivendo neste estágio líquido da modernidade (Bauman, 2001), também valem-se dos meios de comunicação para promover uma aproximação de pensamentos (ou fabricação de consensos, como diriam Hermam \& Chomsky, 2003), com a função "de formar a maior parte das ideias e convicções dos indivíduos e, com isso, orientar todo o seu comportamento social" (Garcia, 2005: 10), facilitando que as sociedades trilhem pelo caminho proposto pelo liberalismo.

O período em que vigorou o regime militar brasileiro (de 1964 até 1985) é outro exemplo significativo da intensa utilização de tais recursos pelo governo ${ }^{1}$, fato que auxiliou a permanência destes no poder por mais de 21 anos, contrariando o ocorrido nos demais países da América Latina, por exemplo: Colômbia, 4 anos; Argentina, 7 anos e Peru e Uruguai, 12 anos. Se compararmos o Brasil e a Argentina, chegamos a uma equação: Repressão X Propaganda Ideológica, sendo que a proporção de cada item pode definir os rumos de tais governos. A Argentina apresentou uma das ditaduras mais sanguinárias, com 30 mil civis assassinados (Castilho, 2013), que culminou com crescentes manifestações populares, fato que contribuiu significativamente para o fim do regime. Enquanto o Brasil, mesmo valendo-se do medo e do terror para conter os grupos organizados e a sociedade de forma geral, o fez de forma mais "calculada" com relação à população, valendo-se de um importante aparato de informação e propaganda.

Todos os presidentes militares utilizaram os meios de comunicação para amparar e legitimar suas ações, bem como apresentar um país não condizente com a realidade vivida naquele momento. Além de possuir um sistema próprio de informações e propagandas ${ }^{2}$, o governo controlava tudo o que era noticiado pelos meios de comunicação de massa. Este controle ocorria pela afinidade ideológica, interesses econômicos dos proprietários, ou, em última instancia, pela censura. A censura, oficializada com o Ato Institucional $\mathrm{n}^{\circ} 5$ - Al- $5^{3}$, impôs um severo sistema de controle das notícias em todos os meios de comunicação.

\footnotetext{
1 Muitos trabalhos já mostraram a utilização dos meios de comunicação pelos governos militares brasileiros com o propósito de persuadir a sociedade em favor da manutenção e dos interesses dos governos militares. Para citar alguns: Fico, 1997; Fiorin, 1988 e Garcia, 2005.

2 A autora chamou de "Complexo Informacional de Sustentação ao Regime Militar" todo o aparato comunicacional desenvolvido pelos governos militares.

3 O Al-5 faz parte de uma série de decretos promulgados pelo governo militar. Este ato foi a expressão máxima da repressão e ofereceu poderes praticamente absolutos aos militares.
} 
No saldo devedor deste período, pode-se também atribuir como algumas das principais consequências para a sociedade brasileira "a alienação produzida pela propaganda, a ignorância sobre as suas próprias condições de vida e seu papel na sociedade." (Garcia, 2005: 18).

Distanciando-se das estratégias utilizadas por regimes anteriores, como o Estado Novo de Getúlio Vargas, as "propagandas" realizadas em prol do regime militar, de maneira geral, não imprimiam as marcas do governo (Fico, 1997; Andrade, 2003). Nesta fase, já não era "tão fácil perceber que se trata de propaganda e que há pessoas tentando convencer outras a se comportarem de determinada maneira. As ideias difundidas nem sempre deixam transparecer sua origem nem os objetivos a que se destinam". (Garcia, 2005: 11).

Assim, temas nacionalistas e de otimismo foram amplamente divulgados (Marconi, 1980; Fico, 1997; Graf, 2003; Garcia, 2005) tanto nas propagandas com marcas oficiais (slogans como "Brasil: ame-o ou deixe-o" e " Ninguém segura este país"), como nas mais diversas notícias da época, em que eram exaltados com certo exagero os feitos militares.

Paralelamente a estas ações realizadas no Brasil, pesquisas comprovaram que a EMBRATUR, criada em 1966, teve o objetivo de modificar a imagem do Brasil como um país violador de direitos humanos, que estava circulando no exterior (Santos Filho, 2004 e 2008 e Damas, 2010). Desta forma, a estratégia do órgão foi utilizar os estereótipos brasileiros já existentes para transmitir a imagem de um país desvinculado dos relatos dos exilados.

Desta forma: (1) Os governos militares valeram-se do sistema de comunicação, inclusive dos particulares, por meio da conivência, coerção ou censura para transmitir uma imagem distorcida da realidade, e ao mesmo tempo (2) os governos militares, por meio da EMBRATUR, buscaram transferir a imagem de um país violento e que não respeitava os direitos humanos para a imagem de um país com lindas paisagens, mulheres bonitas, povo alegre e acolhedor, rico em festas e brilhante no futebol.

Ao refletir sobre estas duas questões surgiu a primeira indagação que deu origem a este trabalho: Será que estes mesmos estereótipos turísticos, indiscriminadamente utilizados pela EMBRATUR para 'maquiar' a imagem do Brasil no exterior também foram usados internamente para manipular a sociedade brasileira a pensar e agir de acordo com os ideais militares e aceitar esta nova condição imposta pós golpe civil-militar? 4

Os resultados preliminares confirmaram a utilização destes estereótipos nas mais variadas notícias e propagandas veiculadas internamente, como poderá ser observado no item "Resultados Preliminares: O Brasil representado pelos estereótipos", apresentado abaixo.

Este artigo foi estruturado da seguinte maneira: Iniciamos falando sobre "O Turismo como Estratégia de Controle Social" e, em seguida apresentamos brevemente o conceito de "Estereótipo", bem como, "Os Estereótipos Turísticos Brasileiros". No item seguinte descrevemos a "Metodologia" utilizada e os "Resultados Preliminares". Para concluir fizemos algumas "Considerações Finais" e apresentamos as "Referências Bibliográficas" utilizadas até o momento.

\footnotetext{
${ }^{4}$ A designação "Golpe Militar", amplamente utilizada na literatura para denominar o Golpe de Estado ocorrido no Brasil em 1964, começou a ser contestada após a publicação do trabalho de René Armand Dreifuss (1981). Nesta obra o autor comprovou a atuação de determinados setores da sociedade civil na efetivação do golpe. Desde então, o termo "golpe civil-militar" tem se demonstrado a definição mais completa para referir-se ao Golpe de Estado consolidado pela ação militar e por este motivo adotou-se esta denominação neste trabalho.
} 


\section{O turismo como estratégia de controle social}

Não é prática recente os governos utilizarem o tema "turismo" como meio de controle social. O turismo é um tema relacionado com o lazer, portanto assunto de fácil aceitação e interesse, além disto, o tema permite a compilação de tudo que há de melhor em um país e isto promove o afloramento de sentimentos como patriotismo e ufanismo. Belezas naturais e construídas, festas populares e até mesmo características do próprio povo, são temas facilmente transformados em produtos turísticos. O processo para transformar tais temas em produtos envolve a criação de estereótipos, ou a reafirmação de um estereótipo já existente e a divulgação interna e externa.

A criação/reafirmação de um estereótipo promove a cristalização do que é "interessante" ser mostrado e, como consequência, a invisibilidade de tudo que não deve/pode/merece ser mostrado. A divulgação deste "produto" permite que os estereótipos sejam difundidos e alcancem números cada vez maiores de pessoas. Com relação à divulgação externa, esta reforça ainda mais o sentimento ufanista da população de dado país, pois transpassa "superioridade" uma vez que reforça o "valor" atribuído ao país por pessoas de outras nações. Um claro exemplo disto foi o vídeo criado pelo Ministério do Turismo - MTur para divulgação do turismo no período da Copa do Mundo de 2014, a primeira frase da peça publicitária expressa esta ideia: "Já imaginou morar em um lugar onde as pessoas passam as férias?" 5

Neste sentido, o tema "turismo" se mostra bastante elástico e permite a adequação aos mais diversos propósitos governamentais, com o benefício da fácil apropriação pela população (sentindo-se fazendo parte do cenário) e da correlação deste "lugar perfeito" com os governos que os administram.

Além disto, o turismo é uma importante peça na engrenagem da ideologia capitalista, funcionando como uma "terapia da sociedade, como válvula que faz manter o funcionamento do mundo de todos os dias. Ele exerce um efeito estabilizador não apenas sobre o indivíduo, mas também sobre toda a sociedade e a economia." (Krippendorf, 2000: 16).

Assim, as estratégias que envolvem o turismo revelam-se como interessante ferramenta para os governos. Não é bastante conveniente para a maior parte dos governos aliar o controle da população e o aquecimento da economia?

Estudos já comprovaram a utilização do turismo por governos autoritários/totalitários. Durante o III Reich de Hitler, o turismo social foi utilizado pelo governo como instrumento de propaganda política. "Infelizmente a Alemanha não foi o único país a utilizar o Turismo Social ${ }^{6}$ com propósitos políticos ocultos, existem registros de outros países que fizeram uso deste segmento para manipular a população a aceitar, agir e pensar de acordo com a ideologia do governo" (Fino \& Silva, 2013:3).

Almeida (2001) cita a utilização do turismo com fins de manipulação pelo governo português, antes e durante o período revolucionário (1974 até 1976), pelo governo canadense, com a ascensão do Partido Quebecois e pela ex-URSS durante o período Estalinista.

O caso que estudaremos neste trabalho refere-se à outra forma de utilização do tema "turismo" como forma de controle da população: O uso de estereótipos pré-existentes para exaltação das qualidades do país, procurando aliá-las a uma "excelente administração pública" e assim esconder as mazelas do regime militar, propiciando um clima otimista na população.

\footnotetext{
5 Vídeo disponível em: http://www.turismo.gov.br/turismo/multimidia/campanhas_publicitarias/ promocao turismo.html. (Acedido em 07/05/2014).

${ }^{6} \mathrm{Em}$ tese, o Turismo Social é um meio de democratizar o acesso às viagens e ao lazer.
} 
Neste caso, a manipulação ocorreu de uma maneira muito sutil, sendo estes temas inseridos no cotidiano das pessoas por intermédio não apenas de propagandas oficiais, mas de inúmeras formas, principalmente inseridas nas mais diversas notícias, auxiliando para que estes estereótipos fossem difundidos no imaginário das pessoas.

\section{O conceito de estereótipo}

O primeiro autor a conceituar estereótipos diz que estes representam certas facetas da realidade, pois "na maioria das vezes, não vemos primeiro para depois definir, mas primeiro definimos e depois vemos. Na grande confusão florida e zunzunante do mundo exterior colhemos o que nossa cultura já definiu para nós, e tendemos a perceber o que colhemos na forma estereotipada, para nós, pela nossa cultura" (Lippmann, 1980: 151).7

Para a sociologia e para a psicologia social estereótipos são imagens pré-concebidas, uma representação coletiva cristalizada construída por fragmentos do todo sob a influência de seu meio social. Desta forma, os estereótipos são criados para simplificar e categorizar o mundo. Segundo Maisonneuve (1977), este mecanismo é inerente ao ser humano, que necessita generalizar para absorver informações, porém estes dizem pouco sobre a realidade e são carregados ideologicamente. Como consequência, os estereótipos dissimulam e reforçam ideologias (Fairclough, 1992). Além disto, os estereótipos são "fonte de construção identitária e fonte simbólica de representações sociais que sobrevivem através dos tempos, reforçandose e fixando-se na memória social” (França, 2012: 47).

Segundo Hintze (2013: 122), estereótipo turístico, chamado pelo autor de "clichê turístico", é algo criado "a partir da redução da complexidade do tipo apresentado [...], por meio do estabelecimento de uma convicção categórica preconcebida sobre algo (ou alguém): o clichê tem a finalidade de um rótulo. É uma forma de preconceito geradora de expectativas, pois promove a possibilidade do estabelecimento antecipado de critérios de julgamento e, é claro, de generalizações.

Hintze (2013) alia a existência de estereótipos turísticos à produção de espetáculos, uma vez que apenas o que é conveniente ser mostrado é traduzido em clichê. Ao mesmo tempo que o espetáculo oferece a materialidade para construção dos estereótipos, ele promove a invisibilidade, ocultando tudo aquilo que não deve/pode/merece ser retratado. $O$ autor conclui que, ao mesmo tempo em que os estereótipos representam uma realidade parcial ou um pseudomundo, eles produzem a invisibilidade (Hintze, 2013).

Os estereótipos são tratados neste trabalho como uma imagem difundida socialmente, carregada ideologicamente, simplista (relatando apenas uma parte do todo), deturpada, que pode levar a uma opinião favorável, ou não, com relação ao tema tratado e que sobrevive através dos tempos.

\subsection{Os estereótipos turísticos brasileiros}

O Brasil está vinculado a alguns estereótipos, sendo que cinco destes foram amplamente utilizados para divulgar o turismo brasileiro no exterior durante o período proposto por esta análise, conforme obra de Bignami (2002), Alfonso (2006) e Kajihara (2008). Abaixo cada um deles será brevemente apresentado.

\footnotetext{
${ }^{7}$ A obra original foi publicada no ano de 1922.
} 


\section{- Brasil Paraíso}

Este é o estereótipo mais antigo, pois desde a descoberta do Brasil "predominou uma imagem associada à grandeza do território, abundância de vida selvagem e sensualidade como dotes naturais (...)." (Nova, 2006: 2). Este estereótipo está relacionado a ideia de Éden, de Eldorado, da Floresta Amazônica, enfim, aos atrativos naturais como recursos inesgotáveis.

\section{- Mulher Brasileira}

Este estereótipo relaciona-se a ideia de sexo fácil e barato, sensualidade, libertinagem e a beleza da mulher brasileira. Provavelmente este é o estereótipo mais utilizado quando falamos em turismo brasileiro, pois muitas vezes dele se apropriam os demais estereótipos. Em muitos casos, quando é identificado um texto ou imagem tipicamente relacionado aos estereótipos "Brasil Paraíso", "Brasil do Brasileiro", "País do Carnaval”, "Lugar do Exótico e do Místico" existe a figura de uma mulher, estrategicamente posicionada.

\section{- Brasil do Brasileiro}

Este estereótipo inclui todas as características atribuídas ao povo brasileiro, como a hospitalidade, a malandragem, a musicalidade, a cordialidade, a alegria e a falta de preconceito.

\section{- País do Carnaval}

Esta denominação sintetiza o imaginário que associa o Brasil com grandes eventos, como o carnaval e o futebol.

\section{- Brasil Exótico e Místico}

Este estereótipo relaciona-se com as manifestações religiosas, a cultura negra e indígena, aos ritos e rituais em geral.

Estas conceituações, propostas inicialmente por Bignami (2002), serão revistas e adaptadas de acordo com os resultados obtidos. De início, já observamos a necessidade de desmembrar o estereótipo Carnaval e Futebol, por representarem características singulares. Desta forma, o estereótipo inicialmente categorizado como "País do Carnaval" foi desmembrado em "País do Carnaval" e "País do Futebol”.

\section{Metodologia}

\subsection{Material e métodos}

Para a realização desta pesquisa foram utilizados os seguintes procedimentos metodológicos: revisão bibliográfica e levantamento documental.

Considerando que o ápice da manipulação e censura durante o militarismo ocorreu desde a criação do Al-5 (Dezembro de 1968) e perdurou até o final do governo Médici, em março de 1974 (os chamados anos de chumbo), o período de análise proposto para esta pesquisa será de 1969 até o primeiro semestre de 1974. Durante este período houve dois tipos de censura "a primeira, através de bilhetinhos e telefonemas que determinavam os assuntos que não deveriam ser abordados pela imprensa; a segunda chamada censura prévia, com censores - 
policiais revisando todo o material a ser divulgado (Marconi, 1980: 43)", inclusive nos meios de comunicações favoráveis ao governo.

A revista Veja foi o objeto de análise deste trabalho devido ao seu alcance nacional e a notória intervenção militar em sua redação durante os anos do regime militar.

A revista Veja esteve sob censura prévia durante 119 edições, tendo 10.352 linhas cortadas, 60 matérias totalmente proibidas, assim como 44 fotografias e 20 desenhos e charges (Marconi, 1980: 84). Isto nos dá nada menos de 87 linhas por número, um artigo vetado a cada dois números, uma foto a cada três e um desenho ou charge a cada seis edições (Soares, 1988: 3).

\subsection{Forma de análise dos resultados}

O período proposto para análise dos dados compreendeu cinco anos e meio. Conforme o Acervo da Revista Veja, representado na Tabela 1, existem 286 edições neste período.

Tabela 1. Número de exemplares por ano

\begin{tabular}{|r|r|}
\hline \multicolumn{1}{|r|}{ ANO } & NÚMERO DE EDIÇÕES \\
\hline 1969 & 53 \\
\hline 1970 & 52 \\
\hline 1971 & 52 \\
\hline 1972 & 52 \\
\hline 1973 & 52 \\
\hline $1^{\circ}$ sem. 1974 & 25 \\
\hline TOTAL & $\mathbf{2 8 6}$ edições \\
\hline
\end{tabular}

Fonte: Elaborada pelas autoras.

Devido ao grande número de exemplares e ao tipo de análise proposta verificou-se que trabalhar com a totalidade do material tornaria a pesquisa inviável. Desta forma, procurou-se trabalhar com uma amostra que permitisse alcançar os objetivos, sem a necessidade de prejuízo do período inicialmente proposto (cinco anos e meio).

A alternativa encontrada foi utilizar o método randômico, selecionando uma revista por mês, sendo que nos anos pares os exemplares serão referentes aos meses pares e nos anos ímpares os exemplares serão referentes aos meses ímpares. Por exemplo, o primeiro ano analisado refere-se a 1969, assim será selecionada uma revista referente a cada um dos meses de janeiro, março, maio, julho, setembro, novembro. No ano de 1970, os meses selecionados foram fevereiro, abril, junho, agosto, outubro e dezembro. A Tabela 2 abaixo representa o número de exemplares que compõem a amostra.

Desta forma mantemos o período total de censura à revista Veja, temos material suficiente para realizar as análises e viabilizamos a realização do trabalho sem prejuízos, conforme proposto inicialmente.

Com relação à forma de análise, foi necessária a leitura integral de cada uma das 33 revistas selecionadas, uma vez que os estereótipos poderiam estar embutidos nas mais variadas sessões. Além das matérias, foram catalogadas capas e propagandas que demonstraram relação com os estereótipos pré-determinados. Sendo assim, a análise contemplou não apenas os textos escritos, como também imagens. 
Tabela 2. Amostra de número de exemplares por ano

\begin{tabular}{|r|r|}
\hline \multicolumn{1}{|c|}{ ANO } & NÚMERO DE EDIÇÕES \\
\hline 1969 & 6 \\
\hline 1970 & 6 \\
\hline 1971 & 6 \\
\hline 1972 & 6 \\
\hline 1973 & 6 \\
\hline $1^{\circ}$ sem. 1974 & 3 \\
\hline TOTAL & 33 edições \\
\hline
\end{tabular}

Fonte: Elaborada pelas autoras.

Esta forma de catalogação nos possibilitou alcançar os primeiros resultados desta pesquisa, além de ser fundamental para a realização da ACD da maneira como propomos. Os dados obtidos nesta etapa nos permitiram não apenas comprovar a utilização dos estereótipos nos textos, mas também o seu intenso uso durante o período e sua pulverização pelas mais variadas sessões da revista. Também nos permitiram ter uma visão global da utilização de cada um deles no decorrer dos cinco anos e meio de análise.

\section{Resultados preliminares: $O$ Brasil representado pelos estereótipos}

Brasil: terra do sol e do mar, das belas mulheres, do povo alegre e hospitaleiro! País rico em belezas e recursos naturais e hegemônico em futebol, carnaval e felicidade. Este foi o Brasil reiteradamente apresentado nos discursos correntes no período analisado, não apenas nos variados meios impressos, como também, em imagens televisivas.

Alguns autores já haviam apontado para o uso da censura com o propósito de implantar um "mundo fictício", em que notícias negativas eram evitadas, buscando transmitir uma imagem de país livre de tensões e conflitos. (Marconi, 1980; Fico, 1997; Alves, 1985; Aquino, 1999). Assim, os estereótipos turísticos brasileiros estavam em consonância com a proposta idealizada pelos militares de criação de um "mundo imaginário", demonstrando apenas aspectos positivos relacionados com o povo e com o país, aspectos estes que, indiretamente, tinham como propósito refletir a imagem do governo vigente.

Leituras empíricas realizadas em material midiático da época (revistas e jornais) apontaram para a constante presença dos estereótipos turísticos, mas foi com a leitura sistemática da revista Veja que pudemos observar a dimensão da utilização discursiva de tais temas.

A presença reiterada destes estereótipos nas páginas da revista Veja pôde ser constatada com a leitura das edições selecionadas. A apresentação de tais temas e figuras foram tão constantes que estavam presentes em todas as edições que compuseram o corpus, além disto, os temas estavam contidos nas mais variadas sessões de Veja, a saber: ambiente, arte, automobilismo, Brasil, ciência, cidades, comportamento, economia e negócios, entrevista, especial, esporte, internacional, literatura, música, imprensa, televisão, teatro, vida moderna entre outras. Além das Capas, Carta ao Leitor, Cartas dos Leitores e propagandas, tanto financiadas pelo governo como por empresas privadas. Esta diversidade de sessões demonstra que, além dos estereótipos estarem presentes nos mais variados assuntos, o alcance aos 
leitores da revista também é ampliado, considerando que cada leitor possui gostos e interesses diferentes uns dos outros.

Outro fator relevante, que representa a intensidade de uso dos estereótipos turísticos, foi a quantidade destes em cada edição e a porcentagem de páginas das matérias que continham menções a um ou mais estereótipos. A Tabela 3 apresenta estas informações.

Tabela 3. Páginas totais e páginas com estereótipos

\begin{tabular}{|c|c|c|c|}
\hline Ano & $\begin{array}{l}\text { Páginas totais da } \\
\text { revista }\end{array}$ & $\begin{array}{l}\text { Páginas - matérias } \\
\text { com estereótipo (s) }\end{array}$ & $\begin{array}{l}\text { Percentual de páginas } \\
\text { com estereótipos }\end{array}$ \\
\hline 1969 & 448 & 98 & $22 \%$ \\
\hline 1970 & 548 & 150 & $27 \%$ \\
\hline 1971 & 544 & 122 & $22 \%$ \\
\hline 1972 & 584 & 89 & $15 \%$ \\
\hline 1973 & 680 & 146 & $21 \%$ \\
\hline $1^{\circ}$ sem. 1974 & 328 & 56 & $17 \%$ \\
\hline
\end{tabular}

Fonte: Elaborada pelas autoras.

Os dados apresentados acima demonstram a quantidade de páginas que fazem referências a um ou mais estereótipos dentre os exemplares da revista Veja que contemplaram o corpus.

Na tabela acima foram excluídas as duplicidades por página, pois em muitos casos, cada matéria possuía mais de um estereótipo, o que na contagem individual gerava um número total muito maior do que os apresentados acima. Em menor quantidade, mas ainda relevante, ocorreram casos em que duas ou mais matérias que continham estereótipos estavam redigidas na mesma página, o que também foi pensado e excluídas as duplicidades das porcentagens citadas na tabela. Desta forma, o número de páginas e as porcentagens representadas são fiéis à realidade, sendo assim, por exemplo, 22\% das páginas das revistas da amostra do ano de 1969 eram páginas que continham um ou mais estereótipos.

Vale lembrar que as matérias foram selecionadas com o máximo de cuidado para apenas serem contabilizadas as que continham a essência dos estereótipos. Assim, por exemplo, não eram todas as matérias que falavam sobre futebol que eram contabilizadas, e sim, as matérias que realmente apresentavam o Brasil como o "país do futebol" de maneira estereotipada. Curiosamente, grande parte dos estereótipos sobre futebol não estavam contidos na sessão “esportes", mas sim pulverizados nas mais variadas sessões. Neste caso em especial, por haver uma sessão específica sobre o tema, percebeu-se mais claramente a busca pela sua naturalização, uma vez que o tema era inserido como algo natural nas notícias sobre os mais variados assuntos.

Como podemos observar, os usos dos estereótipos foram expressivos (o ano com menor representatividade continha $15 \%$ de suas páginas recheadas de estereótipos turísticos 
brasileiros) e demonstram a presença destes estereótipos constantemente nos discursos, sendo que a Revista Veja era apenas um dos meios de que o governo valia-se para introduzir sua ideologia na vida cotidiana da população.

O ano de 1970, tido como o mais repressor, foi também o ano com maior representatividade em utilização de estereótipos na revista Veja, possuindo $27 \%$ de suas páginas contendo um ou mais estereótipos. Estes dados podem indicar relação do momento político com a utilização dos estereótipos.

É interessante notar como os estereótipos pesquisados tornaram-se "invisíveis" para a grande maioria dos leitores, em partes por serem inseridos "sutilmente", em outras pelo fato das pessoas já estarem familiarizadas com estes estereótipos circulando pelos discursos correntes da época. Assim, os discursos impressos faziam parte do cotidiano das pessoas, sendo absorvido inclusive em suas falas, como pôde ser notado em algumas "páginas do leitor", em que os leitores escreviam cartas à redação para comentar sobre matérias de edições anteriores e citavam em seus argumentos clichês como "temos o melhor futebol do mundo" ou "em um país tão rico e belo como o Brasil".

Sobre a inserção dos estereótipos em matérias variadas nota-se que, grande parte das vezes, esta ocorre sem a necessidade de sua presença, ou seja, a ausência destes termos não prejudicaria em nada a informação que a matéria transmite. Como foi o caso da matéria de quatro páginas "De onde vem tanto calor", que ao noticiar sobre as secas de rios, lavouras perdidas e até morte de crianças desidratadas, cita a seguinte frase: "As 63 praias do Rio de Janeiro cobrem-se de torsos nus, maiôs e biquínis" (Veja, 1969: 16). Nota-se que nesta pequena frase se faz referência a dois dos estereótipos pesquisados, um referente ao Brasil paraíso e outro referente ao país de belas (e fáceis) mulheres, frase esta que, como comentado anteriormente, não alteraria o significado da mensagem transmitida nesta matéria.

Abaixo segue Tabela 4, que apresenta o número de matérias e a quantidade de páginas referentes a cada um dos estereótipos.

Tabela 4. Dados quantitativos por estereótipo

\begin{tabular}{|l|r|r|}
\hline Estereótipos & $\begin{array}{r}\text { N. de } \\
\text { Matérias }\end{array}$ & $\begin{array}{r}\text { N. de } \\
\text { Páginas }\end{array}$ \\
\hline Futebol & 105 & 244 \\
\hline Brasil Paraíso & 75 & 208 \\
\hline Sexo Fácil & 75 & 178 \\
\hline Brasil do Brasileiro & 57 & 147 \\
\hline País do Carnaval & 46 & 100 \\
\hline Lugar do Exótico e do Místico & 8 & 17 \\
\hline
\end{tabular}

Fonte: Elaborada pelas autoras. 
Como pode ser observado, dentre os estereótipos pesquisados, o que possuiu maior representatividade foi o "País do Futebol”, com 105 matérias em 244 páginas, seguido dos estereótipos "Brasil Paraíso" e "Sexo Fácil”, ambos com 75 matérias e 208 páginas / 178 páginas respectivamente. Para demonstrar a dimensão destas ocorrências, com relação ao estereótipo "País do Futebol”, havia em média três matérias, com mais de sete páginas por edição da revista.

A próxima etapa, ainda não realizada, nos permitirá compreender como os três estereótipos mais retomados (País do Futebol, Brasil Paraíso e Mulher Brasileira) foram utilizados discursivamente, desvelando o sentido do texto. Desta forma, será possível trazer à superfície parte da estratégia dos governos autoritários que, para grande parte das pessoas na época, estava velada, proporcionando assim, um avanço no debate a partir de tais aspectos.

A título de ilustração, trazemos algumas imagens que demonstram a utilização dos estereótipos pela revista Veja. Nas Figuras 1 e 2 observa-se o estereótipo "Pais do Futebol” nas capas de duas edições da revista Veja. Na primeira (Figura 1), os dizeres "Brasil para sempre" acompanhado da imagem da Taça Jules Rimet, símbolo da vitória da Copa do Mundo de 1970, demonstra a ideia de uma pátria forte e campeã.

Figura 1. Capa Revista Veja Edição 94

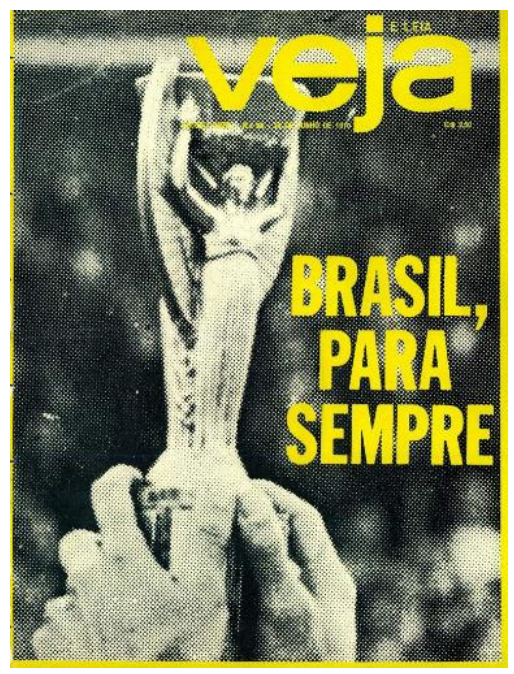

Fonte: Acervo Revista Veja, 1970.
Figura 2. Capa Revista Veja Edição 14

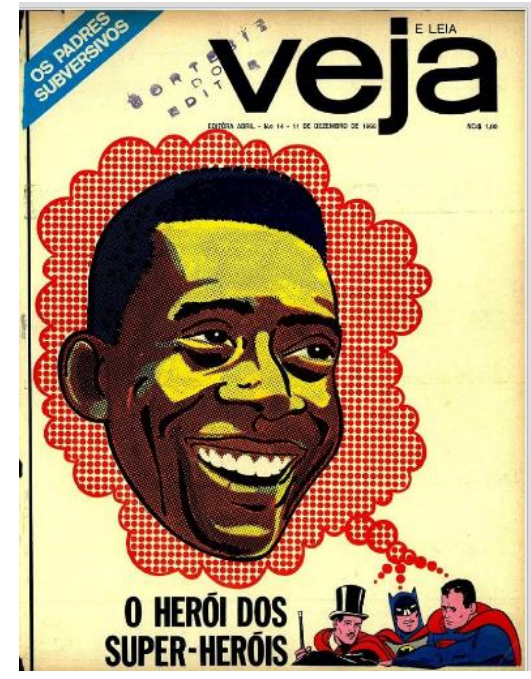

Fonte: Acervo Revista Veja, 1968.

Na segunda (Figura 2), a imagem do Jogador Edson Arantes do Nascimento, o Pelé, sendo apresentado não apenas como um super-herói, mas um super-herói superior aos demais. Construção imagética condizente com a ideia de "rei do futebol", também produzida neste período e até hoje vastamente utilizada.

A Figura 3 é uma das capas que representam o estereótipo "Brasil Paraíso" por meio da valorização das belezas naturais e da tropicalidade. Assim, o azul do mar, as praias ensolaradas, o sol e o céu azul se fizeram presentes, lembrando a todo momento o privilégio de viver em um país dotado de tamanha beleza.

\footnotetext{
${ }^{8}$ Aqui já se fez necessária uma prévia adequação da categorização dos estereótipos. Foi necessário o desmembramento do estereótipo "País do Futebol" que estava contido no estereótipo "País do Carnaval" na obra de Bignami (2002). Este desmembramento se fez necessário devido a representatividade e importância do tema "futebol" no período analisado. Conforme citado anteriormente, será realizada uma proposta de categorização para os estereótipos turísticos brasileiros de acordo com as informações e dados oriundos desta pesquisa.
} 
Figura 3. Capa Revista Veja Edição 75

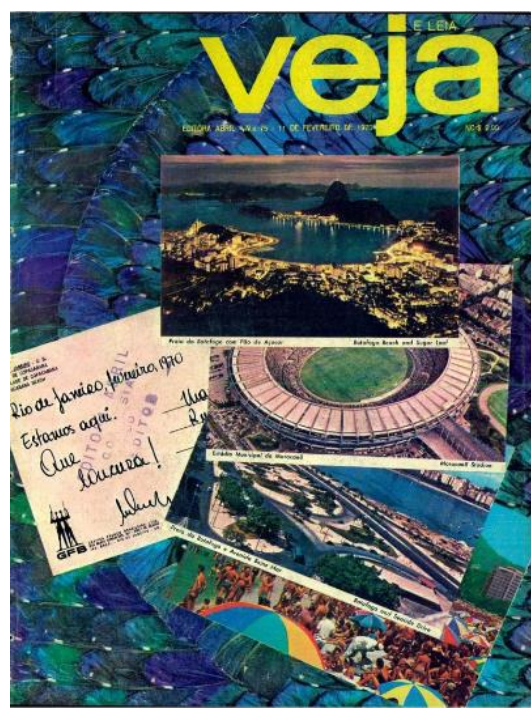

Fonte: Acervo Revista Veja, 1970.

O estereótipo “Mulher Brasileira" também esteve amplamente presente nas páginas da revista Veja. A brasileira foi representada como uma mulher altamente sexualizada, conforme pode ser observado na Figura 4.

Figura 4. Ilustração Matéria Revista Veja Edição 75

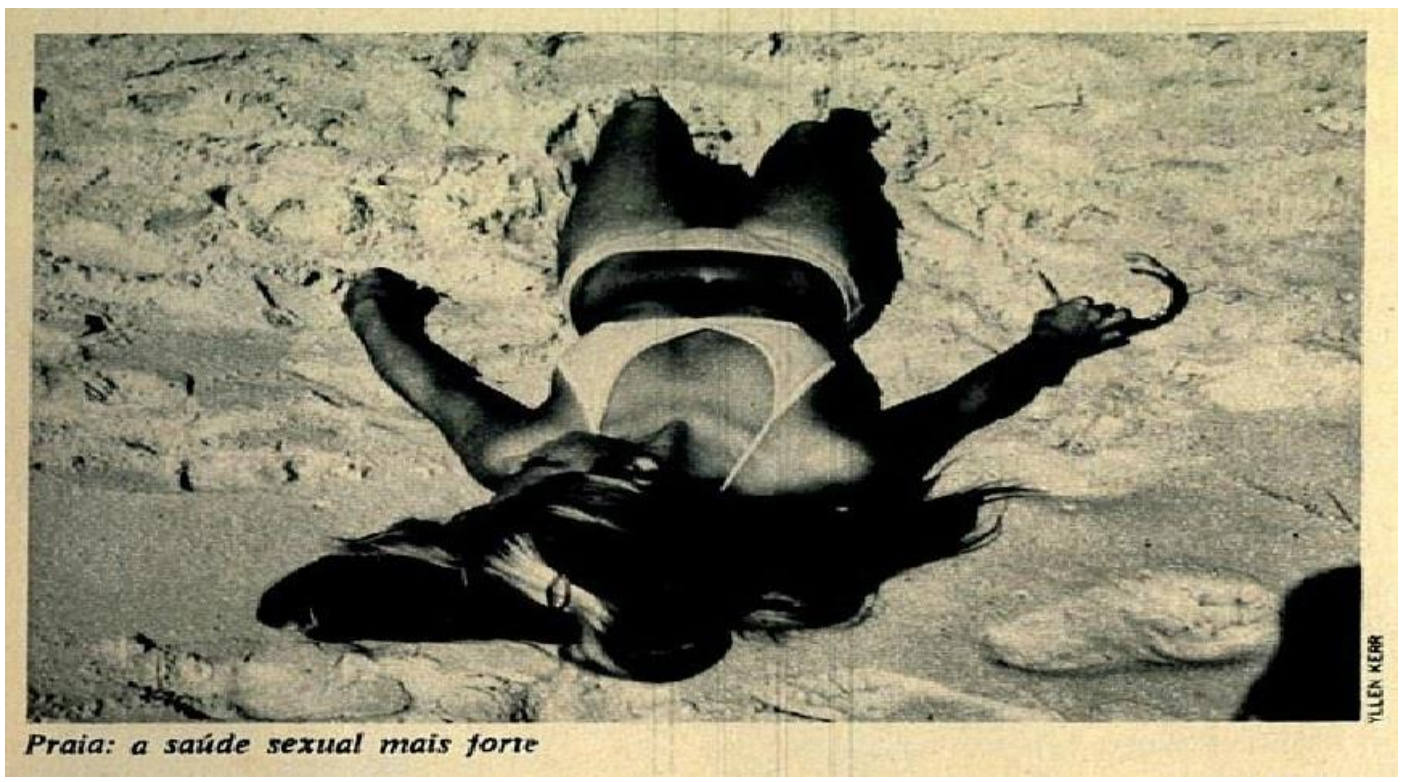

Fonte: Acervo Revista Veja, 1970.

Nesta pesquisa (em andamento) a história será revista e reexaminada perante um aspecto ainda não explorado. Este poderá contribuir para explicar mais um fator que contribuiu para que tivéssemos uma das mais longas ditaduras da América Latina. Além da colaboração histórica, esta também pode ser considerada como um subsídio para a sociedade, que ainda colhe frutos amargos do período. O fim deste regime autoritário não significou o fim dos 
malefícios por ele causados, uma vez tais ações, tão bem arquitetadas e planejadas, deixaram uma herança por todo o tecido social.

\section{Considerações finais}

Conforme os resultados apresentados, o levantamento do corpus confirmou a constante utilização dos estereótipos nas páginas da Revista Veja. Estes estiveram presentes em todas as edições pesquisadas, bem como nas mais variadas sessões da revista. Em média, mais de 20\% de cada exemplar analisado possuíam menções a um ou mais estereótipos, o que inicialmente já comprova a representatividade de seus usos.

Tais referências nas variadas sessões da Revista Veja indicaram a flexibilidade de conexão dos estereótipos com os mais variados assuntos. Esta constatação também apontou para o possível alcance dos estereótipos a todos os leitores da revista, uma vez que não se concentram em sessões específicas, transitando entre aquelas definidas como de "amenidades" até as relacionadas à "economia e negócios", por exemplo. Os temas também estiveram presentes em notícias inesperadas como, por exemplo, na matéria sobre o sequestro do Embaixador da Alemanha que fazia referência ao estereótipo Brasil Paraíso (ed. 94, 1970).

Desta forma, a lente "cor-de-rosa" dos militares também foi sobreposta às notícias cotidianas da revista Veja, sendo os termos inseridos sutilmente, assim como na grande maioria das propagandas oficiais.

Os resultados obtidos até este momento estão em consonância com a hipótese sugerida na proposta inicial deste trabalho, indicando que, os mesmos estereótipos turísticos, indiscriminadamente utilizados pelo governo federal por meio do material da EMBRATUR para 'maquiar' a imagem do Brasil no exterior também foram usados internamente para induzir a sociedade brasileira a não enxergar a realidade como se apresentava, manipulando a população de acordo com os ideais militares, numa tentativa de aceitação da nova condição imposta no pós golpe civil-militar.

Compreender como e de que forma cada um destes estereótipos foram utilizados para alcançar os propósitos de persuasão da população e disseminação da ideologia militar fará parte da próxima etapa deste trabalho, com a realização da Análise Crítica do Discurso.

Segundo Gazzoti, “na época do 'Milagre Econômico' têm-se as campanhas nacionais através de frases como 'Brasil, ame-o ou deixe-o', 'Ninguém segura este país', além da valorização do futebol, temas que procuravam integrar toda a população e colocá-la na defesa do regime militar" (Gazzoti, 1998: 35). Com este estudo pretendemos inserir os estereótipos turísticos neste "patamar" de temas que foram utilizados pelos propósitos militares, estes, não menos relevantes que os demais, porém mais sutis (o que pode ser bastante útil em discursos manipuladores), e dotados de particularidades que, com a finalização deste trabalho, permitirá um maior conhecimento sobre discursos manipuladores (van Dijk, 2012) e este emblemático período.

\section{Referências bibliográficas}

Alfonso, L. (2006). EMBRATUR: Formadora de imagens da nação brasileira. (Dissertação de mestrado não publicada). Universidade de Campinas, SP.

Almeida, M. (2001). Turismo social: Por uma compreensão mais adequada deste fenômeno e sua implicação prática na realidade atual brasileira. (Dissertação de mestrado não publicada). Universidade de São Paulo, SP.

Alves, M. (1985). Estado e oposição no Brasil: 1964-1984. Bauru, SP: EDUSC. 
Andrade, T. (2003). Ecológicas manhãs de sábado. São Paulo: Annablume.

Aquino, M. (1999). Censura, imprensa e Estado Autoritário (1968-1978): O exercício cotidiano da dominação e da resistência. O Estado de São Paulo e Movimento. Bauru: EDUSC.

Bauman, Z. (2001). Modernidade líquida (Trad. P. Souza Dentzien). Rio de Janeiro: Jorge Zahar.

Bignami, R. (2002). A imagem do Brasil no turismo: Construção, desafios e vantagem competitiva. São Paulo: Aleph.

Castilho, A. (2013, 7 junho) Quantas pessoas, de verdade, foram mortas durante a ditadura? Brasil 247.

Damas, H. (2010). Gestão da comunicação no turismo: O caso da Embratur. Revista Espaço Acadêmico, $112,121-127$.

Domenach, J. (2005). A propaganda política [eBook]. Ridendo Castigat Mores.

Dreifuss, R. (1981). 1964: A conquista do Estado. Ação política, poder e golpe de classe. Petrópolis, RJ: Vozes.

Fairclough, N. (1992). Language and power. London: Longman.

Fico, C. (1997). Reinventando o otimismo: Ditadura, propaganda e imaginário social no Brasil. Rio de Janeiro: Fundação Getúlio Vargas.

Fino, P. \& Silva, N. (2013). The study of social tourism: Theory and practice in higher education. Tourism \& Management Studies, 9, $1308-1318$

Fiorin, J. (1988). O Regime de 1964: Discurso e ideologia. São Paulo: Atual.

França, R. (2012). Memória estereotipada: A representação do negro nas páginas da revista Veja. Revista Interin, Curitiba, 14 (2), 46-64.

Garcia, N. (1982). O que é propaganda ideológica. São Paulo: Editora Brasiliense.

Garcia, N. (2005). Propaganda: Ideologia e manipulação [eBook]. Rocket Edition.

Gazzotti, J. (1998). Imprensa e ditadura: A revista Veja e os governos militares. (Dissertação de mestrado não publicada). Universidade Federal de São Carlos, SP.

Graf, M. (2003). Propaganda de lá pra cá. São Paulo: IBRASA.

Hermam, E. \& Chomsky, N. (2003). A manipulação do público: Política e poder econômico no uso da mídia. São Paulo: Futura.

Hintze, H. (2013). Espetáculos e invisibilidades do discurso legitimador do turismo (Tese de doutoramento não publicada). Universidade de São Paulo, SP.

Kajihara, K. (2008). A imagem do Brasil no exterior: Análise do material de divulgação oficial da EMBRATUR, desde 1966 até os dias atuais. (Trabalho de conclusão de curso não publicado). Universidade de São Paulo, SP.

Krippendorf, J. (2000). Sociologia do turismo: Para uma nova compreensão do lazer e das viagens. São Paulo: Aleph.

Lippmann, W. (1980). Estereótipos. In C. Steinberg (Org.), Meios de comunicação de massa. São Paulo: Cultrix.

Maisonneuve, J. (1977). Opiniões e estereótipos. In J. Maisonneuve, Introdução à psicossociologia. São Paulo: Edusp.

Marconi, P (1980). A censura política na imprensa brasileira: 1968-1978. São Paulo: Global.

Martins, R. (1999). Ditadura militar e propaganda política: A revista manchete durante o governo Médici. (Dissertação de mestrado não publicada). Universidade Federal de São Carlos, SP.

Nova, M. (2006). A imagem do Brasil no exterior. Revista Turismo. Disponível em http://www.revistaturismo.com.br/artigos/imagem.html

Pereira. W. (2012). O poder das imagens: Cinema e política nos governos de Adolf Hitler $e$ de Franklin D. Roosevelt (1933-1945). São Paulo: Alameda Editorial.

Santos Filho, J. (2004). EMBRATUR, da euforia ao esquecimento: $O$ retorno às raízes quando serviu à Ditadura Militar. Revista Espaço Acadêmico, 35.

Santos Filho, J. (2008). Ditadura militar utilizou a EMBRATUR para tentar ocultar a repressão, a tortura e o assassinato. Revista Espaço Acadêmico, 84.

Soares, G. (1988). Censura durante o regime autoritário. Revista Brasileira de Ciências Sociais, 10.

Torgal, L. \& Homem, A. (1982). Ideologia Salazarista e "Cultura Popular": Análise da biblioteca de uma casa do povo. Análise Social, vol. XVIII (72-73-74), 1437-1464.

van Dijk, T. (2008). Discourse and context: A sociocognitive approach. New York: Cambridge University Press.

van Dijk, T. (2012). Discurso e poder. São Paulo: Contexto.

Veja [Revista]. Acervo Digital. Disponível em http://veja.abril.com.br/complemento/acervodigital/indexnovo-acervo.html 
PATRÍCIA MARIANA FINO é doutora em Ciências pelo Programa Ecologia Aplicada da Universidade de São Paulo - USP e mestre em Desenvolvimento Regional e Meio Ambiente pela Universidade de Araraquara - UNIARA. Analista crítica de discurso, Bacharel em Turismo, Licenciatura em Geografia, cursando Licenciatura em Pedagogia. Endereço institucional: Universidade de São Paulo. Av. Pádua Dias, 11, Piracicaba/SP, CEP 13418-900 - Brasil.

ODALÉIA TELLES MARCONDES MACHADO QUEIROZ é doutora em Ciências da Engenharia Ambiental pela Universidade de São Paulo - USP e mestre em Geociências e Meio Ambiente pela Universidade Estadual Paulista - UNESP. Possui graduação em Turismo, Geografia e Pedagogia. É docente da ESALQ - Escola Superior de Agronomia Luiz de Queiroz - USP, docente e pesquisadora/ orientadora/ professora do PPG em Ecologia Aplicada/ CENA/ESALQ/USP. Endereço institucional: Universidade de São Paulo. Av. Pádua Dias, 11, Piracicaba/SP, CEP 13418-900 - Brasil.

Submetido em 15 setembro 2016

Aceite em 10 maio 2017 